\title{
Plantar heel pain
}

\author{
Martin J Thomas research fellow and physiotherapy clinical lecturer ${ }^{1}$, Hylton B Menz professor ${ }^{12}$, \\ Christian D Mallen NIHR research professor general practice ${ }^{1}$
}

${ }^{1}$ Arthritis Research UK Primary Care Centre, Keele University, Keele ST5 5BG, UK; ${ }^{2}$ Discipline of Podiatry and La Trobe Sport and Exercise Medicine Research Centre, School of Allied Health, La Trobe University, Bundoora 3086, Victoria, Australia

A 56 year old retail manager complains of four months of pain under her left heel. It is worse first thing in the morning and after sitting.

\section{What you should cover}

About one in 10 people aged over 50 years report plantar heel pain. ${ }^{1}$ A recent ultrasound study of 175 feet with plantar heel pain in a secondary care population diagnosed plantar fasciitis in $73 \%$ of cases. ${ }^{2}$ The symptoms above are typical.

\section{Take a history}

Ask the patient where the pain is and what it feels like. Patients with plantar fasciitis typically describe a sharp pain under the heel. It may extend along the arch of the foot, from the insertion, along the length of the plantar fascia. Pain is worse when taking their initial steps in the morning and eases after a few minutes of walking, but it may return on weight bearing after periods of inactivity during the day. Symptoms are bilateral in about a third of cases. ${ }^{3}$

Explore alternative diagnoses. Trauma from landing on the heel from height can fracture the calcaneum, for example. Previous surgery to the area could lead to longstanding heel pain of iatrogenic causes. If there is pain elsewhere in the body, other symptoms, or systemic upset, consider inflammatory arthropathy. In such cases, the heel stiffness may be prolonged $>30$ minutes in the morning. There may be night pain or prolonged pain when weight bearing has ceased. Bilateral symptoms are common. Ask whether other joints are affected. Suspect malignancy in those with unremitting pain, weight loss, or a history of cancer.

In those with muscle weakness, sensory symptoms, or accompanying leg or back pain, suspect a neurological problem causing referred pain to the foot, such as lumbar spine radiculopathy, nerve entrapment, or tarsal tunnel syndrome.

Consider other risk factors. Ageing is associated with increased heel pad stiffness and plantar fascial thickening, ${ }^{4}$ which can contribute to plantar fasciitis. Standing for long periods is associated with a near fourfold increase and obesity a near sixfold increase in plantar fasciitis. ${ }^{5}$

\section{Examine the patient}

Compare both heels. Point tenderness over the insertion of the plantar fascia on the medial tubercle of the calcaneum, with or without tenderness under the medial longitudinal arch, objectively confirms a clinical diagnosis of plantar fasciitis.

Look and feel for inflammation of soft tissues around the medial aspect of the ankle, heel, and midfoot, which may indicate a tear or rupture, particularly involving tibialis posterior (fig $1 \Downarrow$ ). If no inflammation is present, in those with soft tissue thinning under the heel and more diffuse pain under the heel, suspect fat pad wasting.

\section{What you should do}

- If the working clinical diagnosis is plantar fasciitis, further investigations are rarely needed.

- Explain that plantar fasciitis is swelling of the strap of tissue that supports the arch of the foot.

- Investigate or refer those in whom you suspect undiagnosed inflammatory arthropathy, fracture, or another diagnosis warranting secondary care diagnosis and management.

\section{What to tell the patient}

Explain to the patient that most symptoms usually resolve in 12 months, irrespective of treatment. ${ }^{6}$ In $11 \%$ of people with plantar fasciitis the problem recurs, ${ }^{7}$ and plantar fasciitis is more likely among overweight individuals. ${ }^{8}$ Given that high body mass index is modifiable and weight reduction has multiple other health benefits, advocate active weight management strategies.

Although plantar fasciitis is common we don't have clear evidence on what works best. There are a collection of options which experts think are helpful, and they are set out in clinical 


\section{What you need to know}

- The most common cause of plantar heel pain is plantar fasciitis

- Trial self management for a few months with relative rest, simple analgesia, stretching, weight loss, insoles or arch supports, and footwear modification for patients with plantar fasciitis

guidelines for professionals (for example, the orthopaedic section of the American Physical Therapy Association summarises common strategies ${ }^{9}$ ).

- Advise the patient to rest the foot to some extent for at least six weeks. This patient might seek an alternative working pattern to avoid standing and walking for prolonged periods, which could be supported by a fit note (statement of fitness for work).

- Consider simple analgesia and oral non-steroidal anti-inflammatory drugs if these are not contraindicated. However, no specific evidence of effectiveness exists. ${ }^{10}$

- Expert recommendations suggest that simple exercises, for example rolling the arch of the foot over an object such as a rolling pin or drinks can for a few minutes at least twice a day can help to improve flexibility and relieve pain over a two to eight week period.

- A recent systematic review suggests plantar fascia stretching in addition to Achilles tendon stretching may be beneficial for improving pain and movement (see fig $2 \Downarrow$ for examples). ${ }^{11}$

- Advise the patient to try enclosed supportive footwear. Insoles or arch supports that contour and support the arch can provide pain relief. ${ }^{9}$

Encourage patients to consider all of the above and experiment with what feels more comfortable. If symptoms fail to improve after a few months, consider referral to specialist services such as physiotherapy or podiatry, perhaps guided by the physical appearance of the foot and relative response to first line treatments. ${ }^{10}$

Contributions: All authors contributed to the content, drafting and critical revision of this article before approving the final version.

Funding: MJT is funded by a National Institute for Health Research (NIHR) School for Primary Care Research Launching Fellowship. HBM is currently a National Health and Medical Research Council of Australia senior research fellow (ID 1020925). CDM is funded by the NIHR Collaborations for Leadership in Applied Health Research and Care West Midlands, the NIHR School for Primary Care Research, and a NIHR Research Professorship in General Practice (NIHR-RP-2014-04-026). The views expressed are those of the authors and not necessarily those of the NHS, NIHR, or Department of Health. Competing interests: We have read and understood the BMJ Group policy and declaration of interests and have no relevant interests to declare.

1 Roddy E, Case R, Thomas MJ, et al. Population prevalence and associations of plantar heel pain in adults aged 50 years and over: cross-sectional findings from the Clinical Assessment Study of the Foot. Rheumatology 2015;54(Supplement1):i39-40.

2 Argerakis NG, Positano RG, Positano RC, et al. Ultrasound diagnosis and evaluation of plantar heel pain. J Am Podiatr Med Assoc 2015;105:135-40. doi:10.7547/0003-0538105.2.135pmid:25815653.

3 McMillan AM, Landorf KB, Gilheany MF, Bird AR, Morrow AD, Menz HB. Ultrasound guided corticosteroid injection for plantar fasciitis: randomised controlled trial. $B M J$ 2012;344:e3260. doi:10.1136/bmj.e3260pmid:22619193.

4 Menz HB. Biomechanics of the ageing foot and ankle: a mini-review. Gerontology 2015;61:381-8. doi:10.1159/000368357pmid:25402236.

5 Riddle DL, Pulisic M, Pidcoe P, Johnson RE. Risk factors for Plantar fasciitis: a matched case-control study. J Bone Joint Surg Am 2003;85-A:872-7.pmid:12728038.

6 Buchbinder R. Clinical practice. Plantar fasciitis. N Engl J Med 2004;350:2159-66. doi:10. 1056/NEJMcp032745pmid:15152061.

7 Wolgin M, Cook C, Graham C, Mauldin D. Conservative treatment of plantar heel pain: long-term follow-up. Foot Ankle Int 1994;15:97-102. doi:10.1177/ 107110079401500303 pmid:7951946.

8 van Leeuwen KD, Rogers J, Winzenberg T, van Middelkoop M. Higher body mass index is associated with plantar fasciopathy/'plantar fasciitis': systematic review and meta-analysis of various clinical and imaging risk factors. Br J Sports Med 2015. doi:10. 1136/bjsports-2015-094695. pmid:26644427.

9 Martin RL, Davenport TE, Reischl SF, et al. American Physical Therapy Association. Heel pain-plantar fasciitis: revision 2014. J Orthop Sports Phys Ther 2014;44:A1-33. doi:10. 2519/jospt.2014.0303pmid:25361863

10 National Institute for Health and Care Excellence. Plantar fascitis. Scenario: management (Clinical knowledge summary.) http://cks.nice.org.uk/plantar-fasciitis\#!scenario.

11 Sweeting D, Parish B, Hooper L, Chester R. The effectiveness of manual stretching in the treatment of plantar heel pain: a systematic review. J Foot Ankle Res 2011;4:19. doi: 10.1186/1757-1146-4-19pmid:21703003.

Published by the BMJ Publishing Group Limited. For permission to use (where not already granted under a licence) please go to http://group.bmj.com/group/rights-licensing/ permissions 


\section{Patient resources}

Patient.info. Heel and foot pain (plantar fasciitis). http://patient.info/health/heel-and-foot-pain-plantar-fasciitis

Arthritis Research UK. Exercises to manage foot pain. www.arthritisresearchuk.org/arthritis-information/conditions/foot-pain/foot-painexercises.aspx

\section{Education into practice}

Do you offer a few months of self management before referral?

\section{How patients were involved in the creation of the article}

No patients were involved in the creation of this review.

\section{Figures}

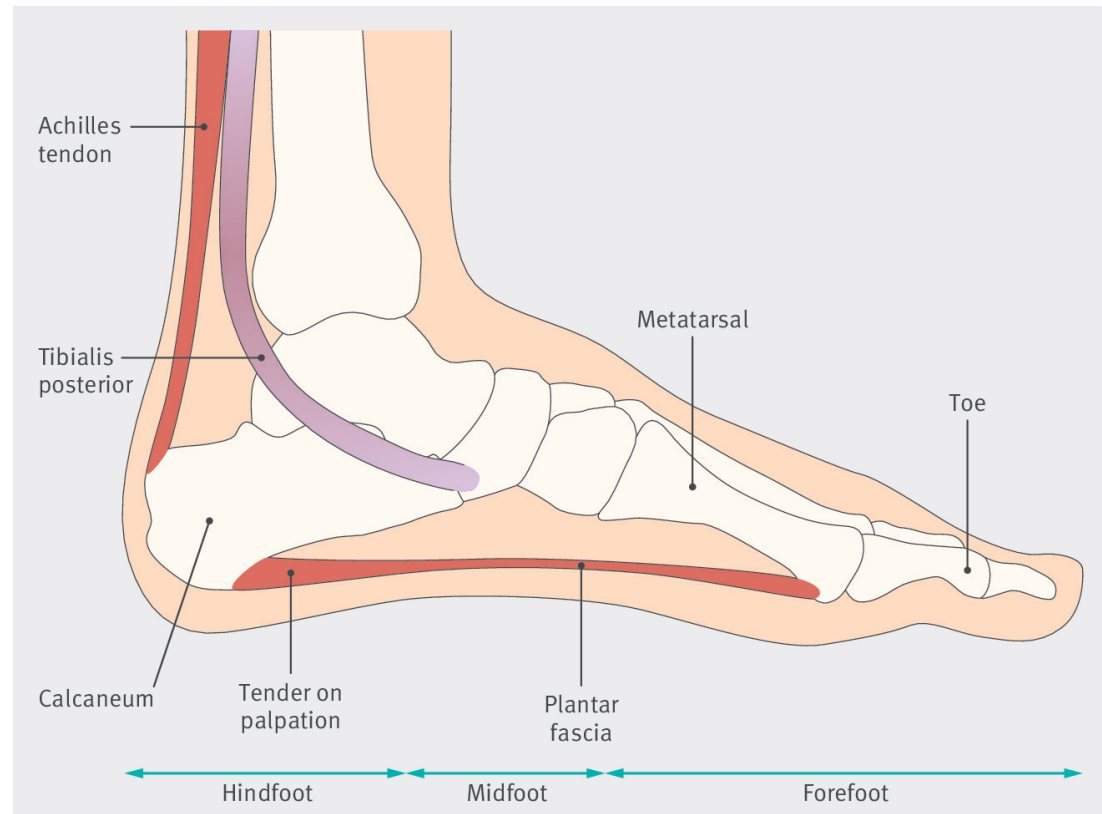

Fig 1 Soft tissue anatomy relevant for differential diagnoses of plantar heel pain. For plantar fasciitis to be confirmed, pain on palpation is felt over the insertion of the plantar fascia on the medial tubercle of the calcaneum. More widespread pain around the medial aspect of the ankle, heel, and midfoot may indicate a tear, particularly along the tibialis posterior. More diffuse plantar pain under the heel may indicate fat pad thinning. 
(ii)
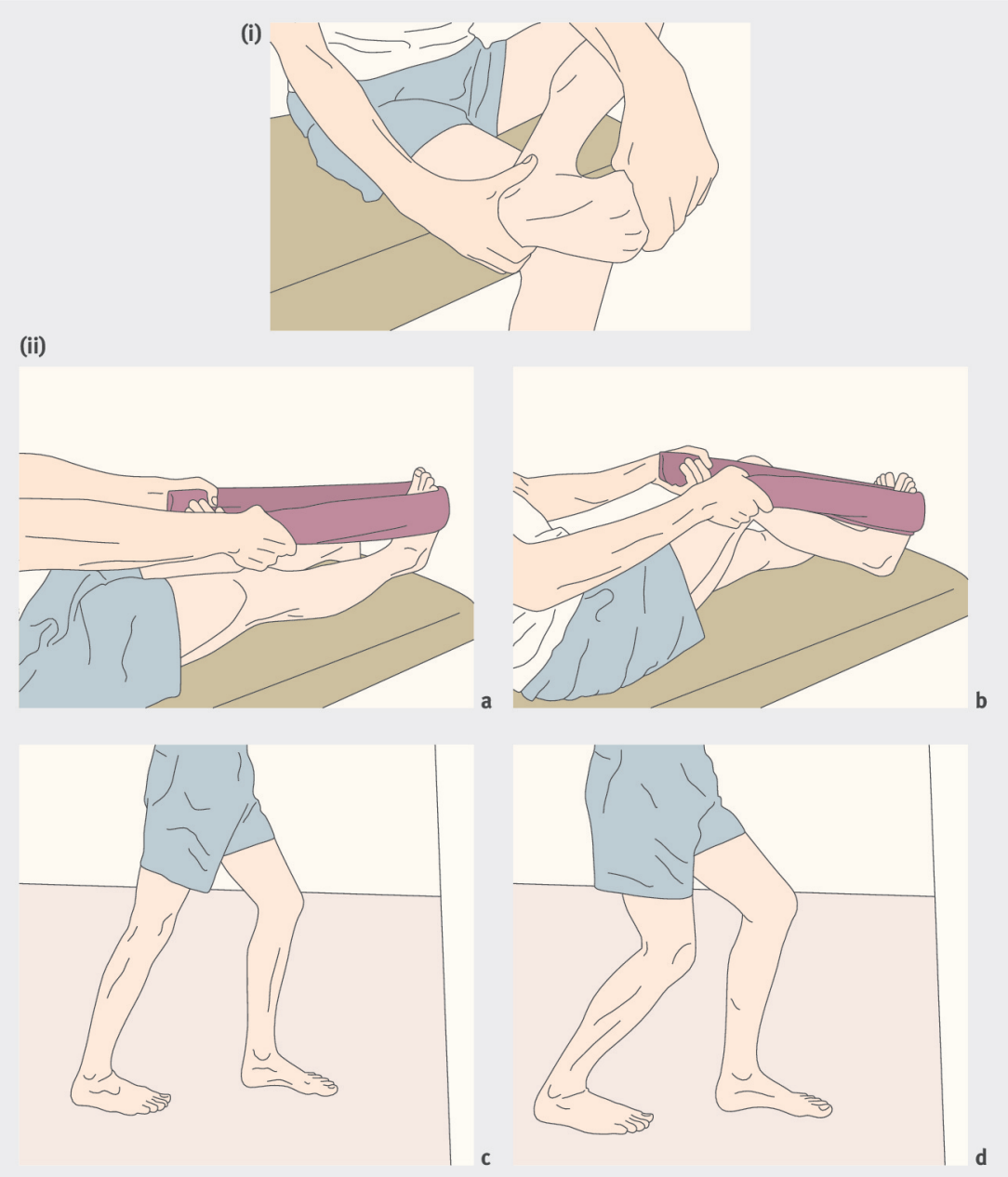

Fig 2 Stretching exercises for plantar heel pain. (i) Plantar fascia stretching: in a comfortable seated position, passively extend the toes. (ii) Calf stretching: sitting with the leg outstretched, hook a towel around the toes and forefoot then pull the foot towards the body into dorsiflexion ( $a$ and $b$ ). As pain allows, progress stretch into weight bearing leaning against a wall (c and d). For both calf stretches, knee straight emphasises the gastrocnemius (a and c) and knee bent emphasises soleus (b and d) 